\title{
ANALISIS HISTORICAL TRADITIONAL FISHING RIGHT PADA ZONA EKONOMI EKSKLUSIF (ZEE) INDONESIA
}

\author{
Satria Unggul Wicaksana Prakasa, Al-Qodar Purwo \\ Fakultas Hukum Universitas Muhammadiyah Surabaya \\ J1. Raya Sutorejo No.59, Mulyorejo, Kota Surabaya, Jawa Timur, Indonesia \\ E-mail : satria@fh.um-surabaya.ac.id
}

\begin{abstract}
Indonesian people are shocked by the case of the Chinese Fisheries (KM) with the name KM Kway Fey 10078 which is categorized as a Foreign Fish Boat (KIA) fishing around the Natuna Islands waters which are the territorial waters of the Indonesian EEZ. The concept of historical traditional fishing ground towards waters in the Natuna sea region which in fact is still an Indonesian EEZ area needs to be further analyzed. The formulation of the problem in legal research are: (1). Theoretical and regulatory regarding Historical Traditonal Fishing Ground based on UNCLOS 1982. (2). The provisions of IUU Fishing are based on UNCLOS 1982 and Indonesian legislation is applied in the case of Historical Traditonal Fishing Ground which catches fish in Indonesian (EEZ) waters. Legal research methods are used with statute approaches and conceptual approaches. The results of this research are (1). If without a bilateral agreement, it is in accordance with the UNCLOS 1982 Historical Traditions of Fishing Ground is categorized as one of the IUU Fishing and violations of jurisdiction and territorial integrity of Indonesia, where Indonesian legal authorities have the right to take action on every fisherman who claims to have traditional fishing rights in accordance with Indonesian legal mechanisms. (2). Needs support from countries to implement policies, programs, and practices from these countries to make this rule implementable, so that there is an impact of remedy for countries that are considered to do IUU Fishing under the pretext of using historical traditional fishing right, then fish commodities arrested was prohibited from being traded on the international market, because the commodity was captured from a process of violation of international marine law and violation of jurisdiction and sovereignty of the State.
\end{abstract}

Keywords : Historical Traditional Fishing Right, UNCLOS 1982, EEZ of Indonesia

\begin{abstract}
Abstrak
Dewasa ini masyarakat Indonesia dikejutkan dengan kasus nelayan Republik Rakyat Tiongkok (RRT) dengan nama kapal KM Kway Fey 10078 yang dikategorikan sebagai Kapal Ikan Asing (KIA) melakukan penangkapan ikan di sekitar perairan Kepulauan Natuna yang merupakan wilayah perairan Zona Ekonomi Eksklusif (ZEE) Negara Indonesia Konsep historical traditional fishing ground terhadap perairan di wilayah laut Natuna yang notabene masih menjadi
\end{abstract}


wilayah ZEE Indonesia perlu dianalisis lebih lanjut. Rumusan masalah dalam penelitian hukum ini adalah: (1).Konsep dasar teoritis serta pengaturan mengenai Historical Traditonal Fishing Ground berdasarkan UNCLOS 1982. (2). Ketentuan IUU Fishing berdasarkan UNCLOS 1982 dan perundang-undangan Indonesia diterapkan pada kasus Historical Traditonal Fishing Ground yang menangkap ikan di perairan (ZEE) Indonesia. Metode penelitian hukum yang digunakan dengan pendekatan perundang-undangan (statute approach) dan pendekatan konseptual (conceptual approach). Hasil penelitian ini adalah (1). Jika tanpa perjanjian bilateral, maka sesuai dengan UNCLOS 1982 Historical Traditonal Fishing Ground dan dikategorikan sebagai satu diantara IUU Fishing dan pelanggaran atas yurisdiksi dan integritas teritorial Indonesia, dimana otoritas hukum Indonesia berhak menindak setiap nelayan yang mengklaim memiliki hak traditional fishing right ditindak sesuai mekanisme hukum Indonesia. (2). Perlu dukungan dari Negara-negara untuk menerapkan kebijakan, program, dan praktik dari Negara-negara tersebut untuk menjadikan aturan ini implementatif, sehingga ada dampak remedy bagi Negara-negara yang dianggap melakukan IUU Fishing dengan dalih pemanfaatan historical traditional fishing right, maka komoditas ikan yang ditangkap dilarang diperjual-belikan dalam pasar internasional, karena komoditas tersebut ditangkap dari proses pelanggaran hukum laut internasional dan pelanggaran terhadap yurisdiksi dan kedaulatan Negara.

\section{Kata Kunci: Historical Traditional Fishing Right, UNCLOS 1982, ZEE Indonesia}

\section{A. PENDAhuluan}

Dewasa ini masyarakat Indonesia dikejutkan dengan kasus nelayan Republik Rakyat Tiongkok (RRT) dengan nama kapal KM Kway Fey 10078 yang dikategorikan sebagai Kapal Ikan Asing (KIA) melakukan penangkapan ikan di sekitar perairan Kepulauan Natuna yang merupakan wilayah perairan Zona Ekonomi Eksklusif (ZEE) Negara Indonesia. KIA tersebut melakukan salah satu diantara tiga (3) jenis kejahatan penangkapan ikan yang disebut Illegal, Unreported, Unregulated (IUU) Fishing. Deteksi target operasi (TO), Sabtu 19 Maret 2016 pukul 14.15 dengan posisi 05 derajat 05,866'N. 109 derajat 07 , 046'6 E, Jarak 2,7 mil haluan 67 derajat. Posisi KIA tersebut berada di wilayah Indonesia. ${ }^{1}$ Yang lebih menarik adalah klaim dari pihak RRT bahwa perairan yang menjadi tempat penangkapan ikan tersebut sebagai wilayah perairan tersebut sebagai wilayah laut sejarah nelayan tradisional (Historical Traditonal Fishing Ground). diganggu kapal coastguard China. Kapal itu dengan sengaja menabrak KM Kway Fey, diduga untuk mempersulit KP Hiu 11 menarik masuk KM Kway Fey. $^{2}$

Perdebatan muncul ketika otoritas terkait Pemerintahan Indonesia dalam hal ini adalah

\footnotetext{
1 http://bisnis.liputan6.com/read/2463504/kronologi-kapal-maling-ikan-asal-tiongkok-dilumpuhkan-dinatuna, diakses pada 15 Mei 2019

${ }^{2}$ https://internasional.kompas.com/read/2016/03/24/20114501/.China.Langgar.Hukum.Laut.di.Natuna. Protes.Keras.Indonesia.Dibenarkan.?page=all, diakses pada 21 Mei 2019
} 
Menteri kelautan dan perikanan (KKP) bersama TNI-AL dengan menggunakan Kapal Hiu 11. Pemerintah Indonesia menyatakan bahwa tidak ada treaty yang mengkonfirmasi bahwa Nelayan RRT berhak melakukan penangkapan ikan di wilayah ZEE Negara Indonesia yang dalam hal ini ada perairan kepulauan Natuna dan dianggap bertentangan dengan ketentuan hukum laut internasional (UNCLOS 1982). ${ }^{3}$

Terlepas dari hal tersebut, disadari bersama bahwa kerugian yang diderita oleh Negara Indonesia baik bersifat materiil maupun inmateriil terkait penangkapan ikan ilegal yang dilakukan oleh nelayan asing, salah satunya dari Indonesia amatlah banyak, kerugian materiil jelas bahwa berbagai macam jenis ikan telah diambil tanpa sepengetahuan negara pantai yang dalam hal ini adalah Negara Indonesia, dan kerugian inmateriil adalah bagaimana kehormatan (dignty) masyarakat Indonesia akan terciderai manakala jika dapat dibuktikan bahwa nelayan RRT melanggar ketentuan hukum nasional namun tidak dapat dijerat hukum oleh Negara Indonesia sebagai salah satu bagian dari menegakkan yurisdiksi dan kedaulatan Negara.

Konsep historical traditional fishing ground yang diklaim oleh nelayan RRT terhadap perairan di wilayah laut Natuna yang notabene masih menjadi wilayah ZEE Indonesia perlu dianalisis lebih lanjut, karena klaim sepihak dari RRT tersebut tidak muncul tiba-tiba, namun sebagai bagian dari dampak Konflik Laut China Selatan (South China Sea Conflict) yang melibatkan beberapa Negara, termasuk irisan wilayah yang diklaim sebagai nine-dash line dan tidak hanya terjadi di laut Natuna, juga perairan di Kepulauan Paracel, Vietnam. Sehingga, jika tidak ada mekanisme penegakkan hukum laut internasional atau keambiguan dalam pengaturan historical traditional fishing right, akan menjadi preseden buruk yang kemudian akan terus berlangsung bagi negara-negara lain melakukan IUU Fishing secara semena-mena dan menerobos yurisdiksi dan kedaulatan hukum di atas laut Indonesia. ${ }^{4}$

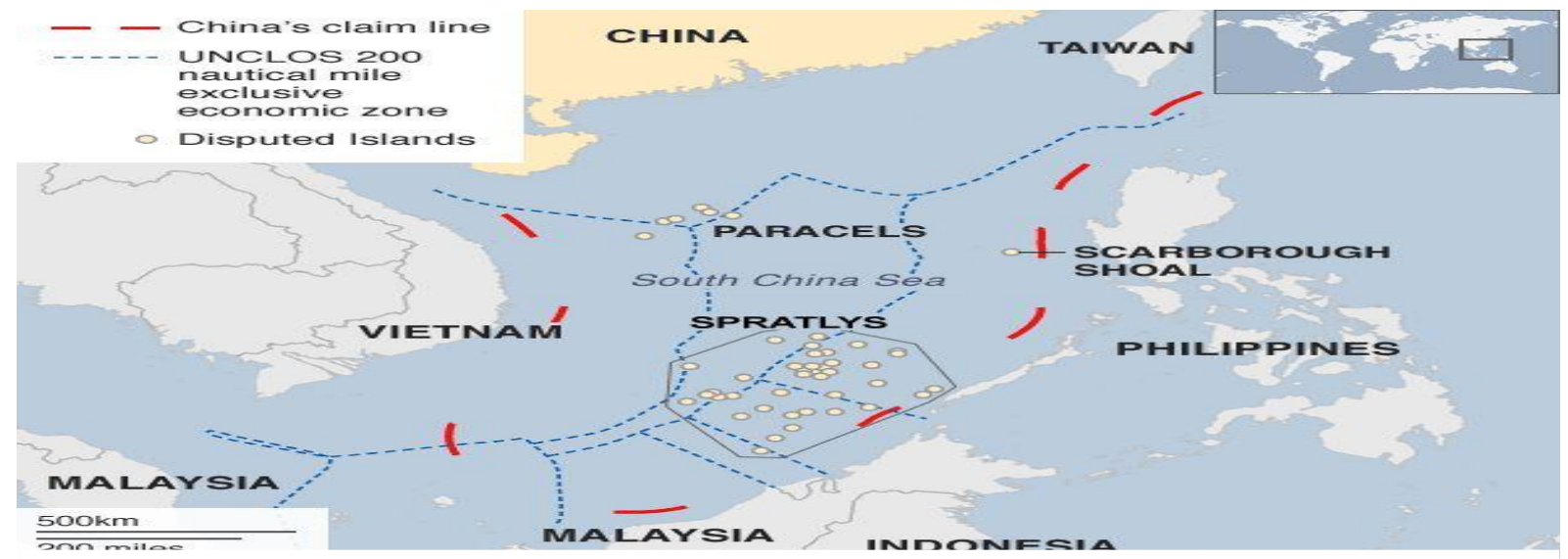

Gambar 1: klaim sepihak nine-dash line RRT yang merugikan banyak Negara, salah satunya Indonesia di perairan Natuna yang diklaim sebagai historical traditional fishing right oleh nelayan RRT.

\footnotetext{
${ }^{3}$ https://economy.okezone.com/read/2016/03/21/320/1342067/begini-kronologis-pelanggaran-kapalchina-versi-menteri-susi, diakses pada 25 Mei 2019

${ }^{4}$ Leszek Buszynski, 2013, The South China Sea Maritime Dispute: Legality, Power, and Conflict Prevention, Asian Journal of Peacebuilding; Seoul Vol. 1, Iss. 1, hlm.39-63.
} 
Isu hukum tersebut menarik untuk dibahas dengan pendekatan UNCLOS 1982 dan perundang-undangan Indonesia sebagai pemegang kedaulatan hukum dan yurisdiksi di Laut Natuna untuk menganalisis diakuinya konsep historical traditional fishing ground, apa dampaknya bagi penegakkan hukum Indonesia, khususnya tentang IUU Fishing, dan bagaimana penyelesaian hukum yang tepat terkait kasus tersebut.

\section{B. RUMUSAN PERMASALAHAN}

Melihat latar belakang yang ada, maka rumusan permasalahan yang diangkat dalam penelitian hukum ini adalah: a) Bagaimana konsep dasar teoritis serta pengaturan mengenai Historical Traditonal Fishing Ground berdasarkan UNCLOS 1982; dan b) Bagaimana ketentuan IUU Fishing berdasarkan UNCLOS 1982 dan perundang-undangan Indonesia diterapkan pada kasus Historical Traditonal Fishing Ground yang menangkap ikan di perairan (ZEE) Indonesia dengan pendekatan hukum internasional dan hukum Indonesia.

\section{METODE PENELITIAN}

Metode penelitian hukum untuk mengetahui apa implikasi hukum dari diakuinya historical traditional fishing ground bagi Negara pantai terhadap ZEE Indonesia yang akan berimplikasi terhadap kedaulatan dan yurisdiksi Negara dengan menggunakan pendekatan perundang-undangan (statute approach). Suatu pendekatan dalam penelitian hukum sebagai suatu proses menemukan aturan hukum, prinsip-prinsip hukum secara doktrinal guna menjawab isu hukum yang sedang diangkat. Pendekatan ini beranjak dari regulasi hukum baik dalam aspek hukum internasional maupun hukum nasional baik bersifat vertikal maupun horizontal, untuk mengkaji aturan hukum yang sejajar atau yang bersifat hierarkis. ${ }^{5}$ Juga melalui pendekatan konseptual (conceptual approach) dengan melakukan analisis terkait isu hukum yang diangkat berdasarkan doktrin dan pandangan para ahli serta pandangan konseptual dan teoritis, hal ini bertujuan untuk memecahkan isu hukum yang diajukan tidak hanya dengan pendekatan perundang-undangan semata yang bersifat terbatas. ${ }^{6}$

Bidang hukum untuk mengkaji historical traditional fishing right bagi Negara-negara lain terhadap ZEE Indonesia adalah kajian hukum internasional publik, khususnya berkaitan dengan hukum laut internasional yang berlandaskan pada United Nations Convention on the Law of the Sea, 1982 (UNCLOS 1982) dan erat kaitannya juga dengan hukum perjanjian internasional yang tunduk pada Vienna Convention on the Law of the Treaties, 1969 (Konvensi Wina 1969), dikarenakan historical traditional fishing ground yang sifat pelanggarannya dan kajian berdasarkan konvensi-konvensi internasional akan menjadi dominan dalam tulisan ini. namun, kajian hukum internasional tidak berdiri sendiri, karena dalam pembahasan tema tersebut juga menggunakan pendekatan hukum laut Indonesia

\footnotetext{
${ }^{5}$ Peter Mahmud Marzuki, 2005, Penelitian hukum, Kencana Prenada Group, Jakarta, hlm. 96-101

${ }^{6}$ Ibid, hlm.137-140.
} 
sebagai rules based system dalam pengaturan dan peruntukkan zonase laut di Indonesia. Artinya, multi-dimensi diskursus akan dibangun dalam penelitian hukum ini sehingga diharapkan akan menghasilkan penelitian hukum yang komprehensif.

Bahan hukum yang telah diperoleh dari konvensi-konvensi hukum internasional, perundang-undangan nasional, kajian literatur berdasarkan tema terkait, maupun dari beberapa kasus yang ada. Dalam penulisan hukum ini akan dianalisis secara kualitatif dengan menggunakan logika deduktif yaitu suatu penarikan kesimpulan dari umum ke khusus.

\section{PEMBAHASAN}

\section{Kerangka Konseptual tentang Traditional Fishing Ground dan Ketentuan Hukumnya Berdasarkan UNCLOS 1982}

Sebagai dasar hukum yang komprehensif tentang hukum laut internasional, UNCLOS 1982, dapat mengakomodir kepentingan Negara-negara peserta dan Negaranegara non-peserta dalam menentukan hukum laut yang digunakan beserta prinsip-prinsip lain tentang hukum laut internasional. Perjanjian internasional yang disetujui di Montego Bay, Jamaika pada tanggal 10 Desember 1982. Konvensi ini ditandatangani oleh 119 Negara yang terdiri dari 17 Bagian (parts), 320 Pasal (article) serta 9 Annex $^{7}$, hingga sampai tahun 2004 sudah diratifikasi oleh 145 Negara. $^{8}$

Dalam ketentuan konvensi ini terdiri atas ketentuan-ketentuan mengenai batasan yurisdiksi suatu Negara di laut dan udara/ Zona Ekonomi Ekslusif (ZEE), konsepsi Negara kepulauan (Archipelagic State), navigasi, perlindungan dan pemeliharaan lingkungan laut, riset ilmiah, pertambangan dasar laut dan eksploitasi lainnya dari sumbersumber non hayati, serta ketentuan terkait penyelesaian perselisihan yang diakibatkan sengketa-sengketa atas wilayah laut, selain itu pembahasan yang tak kalah pentingnya juga mencakup ketentuan mengenai Traditonal Fishing Ground. Dengan cakupan yang luas ini tidak salah bahwa banyak para sarjana yang berpendapat bahwa UNCLOS 1982 merupakan konvensi internasional terlengkap dan ditaati dalam tata perilaku hukum laut internasional.

Terkait dengan ZEE, merupakan zona eksklusif dari suatu Negara pantai untuk menikmati wilayah-wilayah perairan yang termasuk dalam wilayah yurisdiksinya dengan ketentuan 200 mill seperti yang tertera dalam Article 5o7 UNCLOS, yaitu: The exclusive economic zone shall not extend beyond 200 nautical miles from the baselines from which the breadth of the territorial sea is measured, dengan beberapa ketentuan yang dapat

\footnotetext{
${ }^{7}$ Chairul Anwar, Hukum Internasional; Horizon baru hukum internasional konvensi hukum laut 1982, Djambatan, Jakarta, 1989. Hal. 7. Juga dapat dilihat dalam Sahono Soebroto, dkk, Konvensi PBB tentang Laut; Sebuah Tinjauan, Surya Indah, Jakarta,1983. hlm. 9

${ }^{8}$ Boer Mauna, Hukum Internasional; pengertian, peranan dan fungsi dalam era dinamika global, Alumni, Bandung, 2008. Hal. 304
} 
dianalisis pada pasal tersebut adalah: ${ }^{9}$

a. ZEE merupakan hak-hak khusus dari Negara pantai yang mencakup hak dan yurisdiksi dan kekebalan-kekebalan lainnya yang tunduk pada kedaulatan Negaranegara pantai melalui perjanjian tertentu.

b. Hak-hak berdaulat untuk melakukan eksplorasi dan eksploitasi, konservasi dan pengelolaan segala umber kekayaan alam dasar laut dan pada perairan di atasnya. Demikian pula terhadap semua aktivitas yang dtujukan untuk tujuan eksploitasi secara ekonomis dari zona tersebut (seperti produksi energi, arus, dan angin)

c. Yurisdiksi, sebagaimana ketetapan dalam konvensi ini, atas pendirian dan penggunaan pulau-pulau buatan, riset ilmiah kelauatn sertta perlindungan lingkungan laut.

d. Hak-hak dan kewajiban sebagaimana yang ditetapkan dalam konvensi.

Meskipun tertera dalam ZEE adanya hak-hak yang dinikmati oleh Negara-negara pantai maupun non pantai yang berada disekitar ZEE, namun demi kepentingan internasional ada pengecualian-pengecualian hak dari Negara lain yang tidak termasuk dalam wilayah ZEE, seperti yang tertera dalam Article 58 yaitu dalam aspek: ${ }^{10}$

a) Kebebasan pelayaran dan penerbangan

b) Kebebasan meletakkan kabel-kabel di bawah laut dan pipa-pipa dan pemakaian laut lainnya yang dibenarkan secara internasional, seperti yang berkaitan dengan pertalian dan operasi kapal, pesawat terbang, kabel-kabel laut dan pipa-pipa.

Selanjutnya, Negara pantai dengan otoritas yang diberikan oleh UNCLOS 1982 juga berhak menentukan ketentuan-ketentuan yang menjadi prasyarat bagi Negara lain yang melakukan kegiatan penangkapan ikan di wilayah ZEE Negaranya, hal ini sesuai ketentuan Article 62 point 4 dan point 5 yang menyatakan bahwa:

4. Nationals of other States fishing in the exclusive economic zone shall comply with the conservation measures and with the other terms and conditions established in the laws and regulations of the coastal State. These laws and regulations shall be consistent with this Convention and may relate, inter alia, to the following: (a) licensing of fishermen, fishing vessels and equipment, including payment of fees and other forms of remuneration, which, in the case of developing coastal States, may consist of adequate compensation in the field of financing, equipment and technology relating to the fishing industry; (b) determining the species which may be caught, and fixing quotas of catch, whether in relation to particular stocks or groups of stocks or catch per vessel over a period of time or to the catch by nationals of any State during a specified period; (c) regulating seasons and areas of fishing, the types, sizes and amount of gear, and the types, sizes and number of fishing vessels that may be used; (d) fixing the age and size of fish and other species

${ }^{9}$ Louis B. Sohn, et.al, 2014, Cases and Material on the Law of the Sea, Brill Nijhoff Publishing, Leiden, hlm. 52-53

${ }^{10}$ Albert W. Koers, Konvensi Perserikatan Bangsa-Bangsa Tentang Hukum Laut; Sebuat Tinjauan, UGM Press, Yogyakarta, 1994 (Cetakan ke-II), Hlm. 47 
that may be caught; (e) specifying information required of fishing vessels, including catch and effort statistics and vessel position reports; $(f)$ requiring, under the authorization and control of the coastal State, the conduct of specified fisheries research programmes and regulating the conduct of such research, including the sampling of catches, disposition of samples and reporting of associated scientific data; $(g)$ the placing of observers or trainees on board such vessels by the coastal State; ( $h$ ) the landing of all or any part of the catch by such vessels in the ports of the coastal State; (i) terms and conditions relating to joint ventures or other cooperative arrangements; $(j)$ requirements for the training of personnel and the transfer of fisheries technology, including enhancement of the coastal State's capability of undertaking fisheries research; $(k)$ Inforcement procedures.

5. Coastal States shall give due notice of conservation and management laws and regulations.

Agar menjaga hak-hak hukum dari Negara pantai, maka suatu Negara wajib membuat regulasi-regulasi hukum hingga mekanisme teknis, khususnya dalam rangka eksplorasi di wilayah ZEE, seperti mekanisme perizinan, pembayaran, pertukaran informasi, jenis-jenis ikan apa saja yang boleh ditangkap, hingga pelatihan-pelatihan serta riset sebagai implikasi dari perjanjian bersama untuk menikmati hak untuk mengeksplorasi dan mengeksploitasi di wilayah ZEE tersebut.

Terkait dengan historical traditional fishing right, berdasarkan Pasal 51 (1) UNCLOS 1982 menyatakan bahwa:

Without prejudice to article 49, an archipelagic State shall respect existing agreements with other States and shall recognize traditional fishing rights and other legitimate activities of the immediately adjacent neighbouringWithout prejudice to article 49, an archipelagic State shall respect existing agreements with other States and shall recognize traditional fishing rights and other legitimate activities of the immediately adjacent neighbouring States in certain areas falling within archipelagic waters. The terms and conditions for the exercise of such rights and activities, including the nature, the extent and the areas to which they apply, shall, at the request of any of the States concerned, be regulated by bilateral agreements between them. Such rights shall not be transferred to or shared with third States or their nationals. States in certain areas falling within archipelagic waters. The terms and conditions for the exercise of such rights and activities, including the nature, the extent and the areas to which they apply, shall, at the request of any of the States concerned, be regulated by bilateral agreements between them. Such rights shall not be transferred to or shared with third States or their nationals.

Dalam pasal tersebut menentukan bahwa Negara kepulauan harus menghormati perjanjian yang ada dengan Negara lain dan harus mengakui hak perikanan tradisional dan kegiatan lain yang sah Negara tetangga yang langsung berdampingan dalam daerah tertentu yang berada dalam perairan kepulauan. Dimana Syarat dan ketentuan bagi pelaksanaan hak dan kegiatan demikian termasuk sifatnya, ruang lingkup dan daerah wajib diatur dengan perjanjian bilateral antara kedua Negara yang berkepentingan.

Sebagai dampak dari konsep Negara kepulauan, potensi untuk beririsan dengan 
historical traditional fishing ground Negara pantai yang lain, maka wajib kiranya untuk membuat perjanjian bilateral diantara kedua Negara, hal ini secara gamblang dijelaskan dalam Article 47 (6) UNCLOS 1982 yang menjelaskan bahwa "If a part of the archipelagic waters of an archipelagic State lies between two parts of an immediately adjacent neighbouring State, existing rights and all other legitimate interests which the latter State has traditionally exercised in such waters and all rights stipulated by agreement between thoseStates shall continue and be respected".

Konsep tentang historical traditional fishing ground menurut Yoshifuma Tanaka adalah "The term 'historic rights' may be defined as rights over certain land or maritime areas acquired by a State through a continuous and public usage from time immemorial and acquiescence by other States, although those rights would not normally accrue to it under general international law". ${ }^{11}$ Artinya syarat-syarat untuk diakuinya hak tersebut adalah penggunaan secara turun temurun dan berkelanjutan yang tidak lekang waktu, bahkan sebelum UNCLOS 1982 disepakati sebagai rules based system dari hukum laut internasional yang juga mengakomodir adanya pembagian wilayah laut dalam pengaturannya.

Sedangkan menurut James Harrison, sudah menjadi kewajiban Negara pantai untuk mengatur dan menjamin pelaksanaan konservasi sebagai bagian dari implikasi dari menegakkan yurisdiksi, termasuk membuat standar minimum dan perjanjian-perjanjian internasional baik di tingkat regional maupun bilateral, termasuk dalam kaitannya dengan pengaturan tentang historical traditional fishing ground. Agar baik terhadap Negara pantai maupun Negara pengklaim hak historical traditional fishing ground memiliki kewajiban hukum yang sama dalam tanggungjawabnya untuk pemanfaatan sumberdaya perikananan di wilayah laut yang diatur. ${ }^{12}$

Kemudian, menurut Jose Manuel Sobrino \& Marta Sobrido, et.al. menjelaskan lebih spesifik tentang konsep traditional fishing ground adalah memberikan keleluasaan/izin antara coastal state dengan Negara penerima hak untuk menentukan tempat dan daerah pemancingan ikan, fleksibiltas penangkapan ikan tanpa dihalangi oleh otoritas coastal state, dan kesempatan-kesempatan lain yang diperbolehkan antara kedua negara.$^{13}$ Sehingga, hak-hak ekslusif yang sebelumnya secara mutlak berada di tangan Negara pantai akan didelegasikan kepada Negara penikmat hak di wilayah traditional fishing ground.

Terkait dengan hak nelayan tradisional yang ditunjukkan bagi Negara-negara yang berbatasan secara kepulauan yang harus diawali dari permintaan perjanjian bilateral dari

11 Yoshifuma Tanaka, The International Law of the Sea, Cambridge University Press, Eidinburgh, 2012, hlm. 211-212.

12 James Harrison, Making the Law of the Sea: a Study in the Development of Internasional Law, Massachutes: Cambridge University Press, , 2011, hlm. 224.

13 Jose Manuel Sobrino \& Marta Sobrido, et.al, The Future of the Law of the Sea: Bridging Gaps Between National, Individual, and Common Interest, Springer, Roma, 2017, hlm. 38-39 
salah satu pihak. Negara yang selanjutnya akan menikmati hak dari nelayan tradisional tersebut di wilayah ZEE Negara yang termasuk coastal state atau negara pantai yang menikmati hak atas traditional fishing ground, artinya bahwa jelas berdasarkan ketentuan UNCLOS 1982 memberi syarat dan ketentuan tersebut. ${ }^{14}$ Karena perjanjian bilateral yang dibuat antar Negara tetangga akan memberikan legitimasi hukum atas kepentingan historical traditional fishing right yang secara terus menerus dapat dimanfaatkan dan wajib dihormati baik antara Negara pantai dan Negara pemegang hak sebagai dampak Pacta Sunt Servanda dalam perjanjian bilateral yang telah disepakati bersama. ${ }^{15}$

Salah satu praktik terbaik (best practices) yang dilakukan oleh Indonesia sebagai Negara kepulauan dalam rangka menjaga perairan kepulauannya, mengingat jarak antar satu pulau ke pulau lain di Indonesia melebihi 3 Nautical Miles, Indonesia membuat Deklarasi Juanda yang kemudian dibawa dalam proses perundingan hukum laut internasional. Dalam rangka memperkuat legislasi nasional untuk menjaga kedaulatan laut Indonesia, Deklarasi menjadi "ruh" untuk terbitnya Undang-Undang Nomor 4 Prp 1960 tentang perairan Indonesia, Undang-Undang Nomor 8 Tahun 1962 tentang lalu lintas kendaraan air asing di perairan Indonesia, dan Keputusan Presiden Nomor 16 Tahun 1971 tentang wewenang pemberian ijin berlayar bagi segala kegiatan kendaraan air asing dalam wilayah perairan Indonesia untuk kemudian dimasukkan prinsip tersebut dalam UNCLOS $1982 .{ }^{16}$

Indonesia dan Malaysia pernah menuangkan historical traditional fishing right didalam Undang-Undang Nomor 1 Tahun 1983, sebagai konsekwensi dari perjanjian bilateral antara Indonesia dan Malaysia untuk mengakui salah satu wilayah di laut kepulauan Indonesia dapat dimanfaatkan termasuk oleh nelayan-nelayan Malaysia dalam menangkap ikan secara adil dan wajar, ikhwal perjanjian bilateral antara kedua Negara ${ }^{17}$, dapat kita lihat dalam bab penjelasan dari Undang-Undang Nomor 1 tahun 1983, yaitu:

....sebagian laut yang terletak diantara Malaysia Timur dan Malaysia Barat, yang sekarang termasuk kedaulatan teritorial Republik Indonesia berdasarkan Pengumuman Pemerintah mengenai Wilayah Perairan Negara Republik Indonesia pada tanggal 13 Desember 1957 yang kemudian dikenal sebagai Deklarasi Djuanda dan yang selanjutnya telah dikukuhkan dengan Undang-undang Nomor 4 Prp Tahun 1960 tentang Perairan Indonesia, semula adalah laut bebas.

Yang dimaksudkan dengan hak-hak tradisional dan kepentingan-kepentingan yang sah Malaysia yang telah ada di wilayah laut tersebut pada pokoknya meliputi hak akses dan komunikasi baik di laut maupun di udara bagi kapal-kapal dan pesawat udara Malaysia untuk tujuan dagang, sipil dan militer dan hak perikanan tradisional Malaysia di

14 Julian Roberts, 2007.Marine environment protection and biodiversity conservation; the Aplication and Future Development of the IMO's Particulary Sensitive Sea Area Concept, Leipzig; Springer, hlm. 47

15 George K. Walker, 2012, Definitions for the Law of the Sea: Terms Not Defined by the 1982 Convention, Martinus Nijhoff Publishing, Leiden, hlm. 89

${ }^{16}$ Dina Sunyowati dan Enny Narwati, Buku Ajar Hukum Laut, Airlangga University Press, Surabaya, 2013, hlm. 19-20

${ }^{17}$ Yoshifuma Tanaka, Op.Cit, hlm. 112. 
tempat-tempat tertentu di wilayah laut, termasuk hak memasang kabel telekomunikasi dan pipa-pipa bawah lau.

Dengan adanya Perjanjian antara Republik Indonesia dan Malaysia yang telah ditandatangani di Jakarta pada tanggal 25 Pebruari 1982, Rejim Hukum Negara Nusantara telah mendapatkan pengakuan yang sah oleh Malaysia. Hal ini penting artinya di dalam situasi di mana Konvensi Hukum Laut yang baru belum ditandatangani dan mempunyai dampak baik di bidang politik maupun di bidang hukum internasional, terlebih lagi karena pengakuan secara hukum telah diberikan oleh suatu negara tetangga Indonesia dan yang letaknya terdekat di lingkungan ASEAN (Association of South East Asian Nations)......

Undang-Undang Nomor 1 tahun 1983 menjadi petunjuk, bahwa dalam pendelegasian hak laut tradisional kepada Negara lain, wajib dituangkan dalam perjanian bilateral atau dalam perjanjian-perjanjian internasional yang lain yang tunduk berdasarkan Konvensi Wina 1969 (Vienna Convention on the law of the Treaties 1969) yang mana dalam sistem hukum Indonesia dituangkan dalam Undang-Undang Nomor 24 Tahun 2000 tentang Perjanjian Internasional, khususnya pada Pasal 10 huruf (b) dan huruf (c) terkait: "Pengesahan perjanjian internasional dilakukan dengan undang- undang apabila berkenaan dengan :...b. perubahan wilayah atau penetapan batas wilayah negara Republik Indonesia; c. kedaulatan atau hak berdaulat negara;... “. ". Historical traditional fishing ground yang dibuat dalam perjanjian internasional sangat berkaitan dengan delimitasi wilayah laut dan menyangkut hak berdaulat Negara yang harus diratifikasi dalam bentuk Undang-Undang (ada persetujuan antara eksekutif dan legislatif). ${ }^{18}$

International Court of Justice (ICJ) pernah memutuskan kasus historical rights di perairan yang berbatasan antara Tunisia dan Libya, dan dalam kasus ini ICJ menganggap tidak perlu memutuskan keabsahan historical traditional fishing right terhadap Libya, karena secara geografis hak tersebut telah dilaksanakan berangsur-angsur secara konsisten oleh nelayan Tunisia di wilayah tersebut. ${ }^{19}$ Dalam praktik Negara, ada perjanjian bilateral dan India pada 1976 untuk menjawab persoalan terkait pembatasan wilayah laut sejarah yang timbul diantara kedua Negara tersebut, perjanjian internasional tersebut menjadi penyelesaian persoalan yang selama ini timbul diantara kedua Negara terkait historical traditional fishing ground..$^{20}$

Sehingga, jika tanpa perjanjian bilateral tersebut maka sesuai dengan UNCLOS 1982 yang berkaitan dengan traditional fishing right, dalam hal tersebut dilakukan oleh nelayan RRT disebut Historical Traditonal Fishing Ground tidak dibenarkan sesuai ketentuan hukum internasional dan dikategorikan sebagai satu diantara IUU Fishing dan pelanggaran atas yurisdiksi dan integritas teritorial Indonesia, dimana otoritas hukum

${ }^{18}$ Damos Dumoli Agusman, Hukum Perjanjian Internasional: Kajian Teori dan Praktik Indonesia (Cet. Ke-2), Refika Aditama, Bandung, hlm. 31-32

${ }^{19}$ ICJ Reports 1982, p. 73, para. 100. p. 75, para. 102, Ibid, hlm. 211

${ }^{20}$ Ibid, hlm. 212. 
Indonesia berhak menindak setiap nelayan yang mengklaim memiliki hak traditional fishing right ditindak sesuai mekanisme hukum Indonesia.

\section{Regulasi-regulasi Hukum Internasional Mengenai IUU Fishing}

Selain UNCLOS 1982, ketentuan-ketentuan hukum lain yang bersifat lebih teknis mengatur mengenai IUU Fishing sebagai instrumentasi hukum internasional atas pelanggaran klaim historical traditional fishing right tersebut. Berdasarkan ketentuan Agenda-21 Johanesburg, khususnya dalam section 17.3 menyatakan bahwa Negara-negara di muka bumi diupayakan menjaga wilayah ZEE dalam rangka pengaturan dan pengembangan budidaya hasil laut agar tidak terjadi penyalahgunaan pengelolaan sumber daya laut, salah satunya berkaitan dengan antisipasi atas pelanggaran IUU Fishing serta ketentuan tersebut menjadi petunjuk bagi Negara-negara untuk membuat regulasi nasional mengenai pengelolaan dan pemanfaatan hasil laut. Indonesia telah mempunyai UndangUndang Nomor 31 Tahun 2004 dan Undang-Undang Republik Indonesia Nomor 45 Tahun 2009 Tentang Perubahan Atas Undang-Undang Nomor 31 Tahun 2004 Tentang Perikanan, sebagai bagian dari menjalankan kekuasaan dan kemampuannya dalam menjaga yurisdiksi dan kedaulatan laut. ${ }^{21}$

Selanjutnya, dalam United Nations Conference On Straddling Fish Stocks And Highly Migratory Fish Stocks 1995 (UNIA 1995) yang telah diratifikasi dalam sistem hukum Indonesia pada UU Nomor 21 Tahun 2009, pada Article 8 konvensi ini menyatakan bahwa:

(1.) Coastal States and States fishing on the high seas shall, in accordance with the Convention, pursue cooperation in relation to straddling fish stocks and highly migratory fish stocks either directly or through appropriate subregional or regional fisheries management organizations or arrangements, taking into account the specific characteristics of the subregion or region, to ensure effective conservation and management of such stocks. (2.) States shall enter into consultations in good faith and without delay, particularly where there is evidence that the straddling fish stocks and highly migratory fish stocks concerned may be under threat of overexploitation or where a new fishery is being developed for such stocks. To this end, consultations may be initiated at the request of any interested State with a view to establishing appropriate arrangements to ensure and management of the stocks. Pending agreement on such arrangements, States shall observe the provisions of this Agreement and shall act in good faith and with due regard to the rights, interests and duties of other States. (3.) Where a subregional or regional fisheries management organization or arrangement has the competence to establish conservation and management measures for particular straddling fish stocks or highly migratory fish stocks, States fishing for the stocks on the high seas and relevant coastal States shall give effect to their duty to cooperate by becoming members of such organization or participants in such arrangement, or by agreeing to apply the conservation and management measures established by such

${ }^{21}$ Natalie Klein, 2010, Maritime Secuirity and the Law of the Sea, Oxfordshire: Oxford University Press, hlm. 90 
organization or arrangement. States having a real interest in the fisheries concerned may become members of such organization or participants in such arrangement. The terms of participation in such organization or arrangement shall not preclude such States from membership or participation; nor shall they be applied in a manner which discriminates against any State or group of States having a real interest in the fisheries concerned.

Dalam ketentuan tersebut, baik coastal state maupun state fishing harus mengadakan kerjasama bilateral dalam hal pengolaan hingga konsultasi dengan itikad baik, baik antarnegara dan dimungkinkan perjanjian bilateral dengan organisasi internasional dalam hal mengatur mengenai eksploitasi dalam sektor perikanan tersebut, hal ini bertujuan agar tidak terjadi over-exploitation dalam hal penangkapan ikan dan terjadi pertikaian antar kedua negara yang diakibatkan dari praktik-praktik illegal yang menciderai perdamaian dan keamanan dari masing-masing negara, sehingga tindakan kooperatif internasional yang ditandai dengan perjanjian internasional baik bilateral, trilateral, atau multilateral perlu dibuat, ${ }^{22}$ agar tidak terjadi klaim sepihak dengan dalih historical traditional fishing right kemudian menjadi alasan bagi pelanggaran IUU Fishing.

Selanjutnya, didalam Code Of Conduct For Responsible Fisheries (CCRF)- FAO 1995 pada Article 2.1 menyatakan bahwa cakupan dari Code Of Conduct bersifat global, mulai dari Negara hingga nelayan harus menjadikan peraturan ini sebaga tata perilaku dalam pemanfaatan sumber daya perikanan hingga dalam aspek penjualan dari ikan itu sendiri agar tidak melanggar ketentuan hukum internasional lainnya, karena berdasarkan Article 3 menyatakan bahwa pada aturan hukum ini juga mengacu kepada UNCLOS 1982 dan Agenda-21, Johanesburg.

Pada Article 6.14 CCRF-FAO 1995 memberikan penjelasan bahwa:

International trade in fish and fishery products should be conducted in accordance with the principles, rights and obligations established in the World Trade Organization (WTO) Agreement and other relevant international agreements. States should ensure that their policies, programmes and practices related to trade in fish and fishery products do not result in obstacles to this trade, environmental degradation or negative social, including nutritional, impacts....

Artinya dalam ketentuan ini, penjualan hasil dari perikanan harus sesuai dengan ketentuan WTO dan memperhatikan aspek perlindungan terhadap hasil laut tersebut tidak menimbulkan degradasi moral, memperburuk kualitas gizi, dsb. Poin penting dari pasal ini adalah terkait pelarangan hasil IUU Fishing untuk dilaksanakan ekspor/impor dan dapat dikategorikan prohibited transaction. ${ }^{23}$ Sehingga produk-produk perikanan yang menjadi komoditas yang tersirkulasi dalam perdagangan internasional bagi Negara-negara anggota wajib menolak (banned) agar Negara yang sering menerobos yurisdiksi dan kedaulatan

${ }^{22}$ Douglas Goilfoyle, Shipping Interdiction and the Law of the Sea, Cambridge University Press, Massachutes, 2009, hlm. 110-111

${ }^{23}$ Margareth A.Young, The 'Law of the Sea' Obligations Underpinning Fisheries Subsidies Disciplines, International Centre for Trade and Sustainable Development (ICTSD) Publisher, Geneva, 2017, hlm. 4-5 
negara mendapatkan implikasi negatif dari praktik pelanggaran yurisdiksi dan kedaulatan negara.

Maka dari itu perlu dukungan dari Negara-negara untuk menerapkan kebijakan, program, dan praktik dari Negara-negara tersebut untuk menjadikan aturan ini implementatif, sehingga ada dampak remedy bagi Negara-negara yang dianggap melakukan IUU Fishing dengan dalih pemanfaatan historical traditional fishing right maka komoditas ikan yang ditangkap dilarang diperjual-belikan dalam pasar internasional, karena komoditas tersebut ditangkap dari proses pelanggaran hukum laut internasional dan pelanggaran terhadap yurisdiksi dan kedaulatan Negara.

\section{E. PENUTUP}

Berdasarkan analisis dan pembahasan ddiatas, dapat disimpulkan bahwa jika tanpa perjanjian bilateral, maka sesuai dengan UNCLOS 1982 Historical Traditonal Fishing Ground dan dikategorikan sebagai satu diantara IUU Fishing dan pelanggaran atas yurisdiksi dan integritas teritorial Indonesia, dimana otoritas hukum Indonesia berhak menindak setiap nelayan yang mengklaim memiliki hak traditional fishing right ditindak sesuai mekanisme hukum Indonesia. Perlu dukungan dari Negara-negara untuk menerapkan kebijakan, program, dan praktik dari Negara-negara tersebut untuk menjadikan aturan ini implementatif, sehingga ada dampak remedy bagi Negara-negara yang dianggap melakukan IUU Fishing dengan dalih pemanfaatan historical traditional fishing right, maka komoditas ikan yang ditangkap dilarang diperjual-belikan dalam pasar internasional, karena komoditas tersebut ditangkap dari proses pelanggaran hukum laut internasional dan pelanggaran terhadap yurisdiksi dan kedaulatan Negara.

Penghormatan terhadap yurisdiksi dan kedaulatan Negara di atas laut itu sangat penting, artinya pemanfaatan dan eksplorasi serta eksploitasi kekayaan alam di wilayah laut yang bersifat lintas batas Negara harus dituangkan dalam perjanjian internasional. Menilik klaim sepihak RRT atas historical traditional fishing ground, seharusnya pihak RRT menyampaikan permohonan maaf secara resmi melalui saluran diplomatik, karena apabila nelayan RRT ataupun nelayan asing lainnya menerobos hak kedaulatan kita, otoritas hukum kita legal untuk menindaknya, implikasi dari hal tersebut akan berpengaruh terhadap hubungan diplomatik antar Negara yang berkepentingan, dan ini jelas bagian dari gangguan terhadap perdamaian dan stabilitas kawasan

\section{DAFTAR PUSTAKA}

Albert W. Koers, Konvensi Perserikatan Bangsa-Bangsa Tentang Hukum Laut; Sebuat Tinjauan, UGM Press, Yogyakarta, 1994 (Cetakan ke-II)

Boer Mauna, Hukum Internasional; pengertian, peranan dan fungsi dalam era dinamika global, Alumni, Bandung, 2008 
Chairul Anwar, Hukum Internasional; Horizon baru hukum internasional konvensi hukum laut 1982, Djambatan, Jakarta, 1989.

Code Of Conduct For Responsible Fisheries (CCRF)- FAO 1995

Damos Dumoli Agusman, Hukum Perjanjian Internasional: Kajian Teori dan Praktik Indonesia (Cet. Ke-2), Refika Aditama, Bandung, 2014.

Dina Sunyowati dan Enny Narwati, Buku Ajar Hukum. Laut, Airlangga University Press, Surabaya, 2013.

Douglas Goilfoyle, Shipping Interdiction and the Law of the Sea, Cambridge University Press, Massachutes, 2009

George K. Walker, Definitions for the Law of the Sea: Terms Not Defined by the 1982 Convention, Martinus Nijhoff Publishing, Leiden, 2012

http://bisnis.liputan6.com/read/2463504/kronologi-kapal-maling-ikan-asal-tiongkokdilumpuhkan-di-natuna , diakses pada 15 Mei 2019

https://economy.okezone.com/read/2016/03/21/320/1342067/begini-kronologis-pelanggarankapal-china-versi-menteri-susi , diakses pada 25 Mei 2019

https://internasional.kompas.com/read/2016/03/24/20114501/.China.Langgar.Hukum.Laut.di. Natuna.Protes.Keras.Indonesia.Dibenarkan.?page=all , diakses pada 21 Mei 2019

https://www.bbc.com/news/world-asia-pacific-13748349, diakses pada 27 Mei 2019

James Harrison, Making the Law of the Sea: a Study in the Development of Internasional Law, Massachutes: Cambridge University Press, 2011

Jose Manuel Sobrino \& Marta Sobrido, et.al, The Future of the Law of the Sea: Bridging Gaps Between National, Individual, and Common Interest, Springer, Roma, 2017.

Julian Roberts, Marine Environment Protection and Biodiversity Conservation; the Aplication and Future Development of the IMO's Particulary Sensitive Sea Area Concept, Springer, Leipzig, 2007

Leszek Buszynski, 2013, The South China Sea Maritime Dispute: Legality, Power, and Conflict Prevention, Asian Journal of Peacebuilding; Seoul Vol. 1, Iss. 1, Pg.39-63

Louis B. Sohn, et.al, Cases and Material on the Law of the Sea, Brill Nijhoff Publishing, Leiden, 2014.

Margareth A.Young, The 'Law of the Sea' Obligations Underpinning Fisheries Subsidies Disciplines, International Centre for Trade and Sustainable Development (ICTSD) Publisher, Geneva, 2017

Natalie Klein, Maritime Secuirity and the Law of the Sea, Oxfordshire: Oxford University Press, 2010. 
Peter Mahmud Marzuki, Penelitian hukum, Kencana Prenada Group, Jakarta, 2005.

Undang-Undang Republik Indonesia Nomor 1 Tahun 1983 Tentang Pengesahan Perjanjian Antara Republik Indonesia Dan Malaysia Tentang Rejim Hukum Negara Nusantara Dan Hak-Hak Malaysia Di Laut Teritorial Dan Perairan Nusantara Serta Ruang Udara Diatas Laut Teritorial, Perairan Nusantara Dan Wilayah Republik Indonesia Yang Terletak Di Antara Malaysia Timur Dan Malaysia Barat (LN 1983/7; TLN NO. 3248)

Undang-Undang Republik Indonesia Nomor 24 Tahun 2000 Tentang Perjanjian Internasional (Lembaran Negara Republik Indonesia Tahun 2000 Nomor 185, Tambahan Lembaran Negara Republik Indonesia Nomor 4012)

Undang-Undang Republik Indonesia Nomor 45 Tahun 2009 Tentang Perubahan Atas Undang-Undang Nomor 31 Tahun 2004 Tentang Perikanan

United Nation Convention on The Law of The Sea 1982 (Ratifikasi dalam Undang-Undang Republik Indonesia Nomor 17 Tahun 1985 Tentang Pengesahan United Nations Convention on the Law of the Sea (Konvensi Perserikatan Bangsa-Bangsa Tentang Hukum Laut Lembaran Negara Republik Indonesia Tahun 1985 Nomor 76))

United Nations Conference On Straddling Fish Stocks And Highly Migratory Fish Stocks 1995 (Ratifikasi dalam Undang-Undang Republik Indonesia Nomor 21 Tahun 2009 Tentang Pengesahan Agreement for the Implementation of the Provisions of the United Nations Convention on the Law of the Sea of 10 December 1982 Relating to the Conservation and Management of Straddling Fish Stocks and Highly Migratory Fish Stocks (Persetujuan Pelaksanaan Ketentuan-Ketentuan Konvensi Perserikatan BangsaBangsa Tentang Hukum Laut Tanggal 10 Desember 1982 Yang Berkaitan Dengan Konservasi dan pengelolaan sediaan ikan yang beruaya terbatas Dan sediaan ikan yang beruaya jauh))

Yoshifuma Tanaka, The International Law of the Sea, Cambridge University Press, Eidinburgh, 2012. 